View Article Online / Journal Homepage / Table of Contents for this issue

ROTATORY POWER OF OPTICALLY ACTIVE NITROGEN COMPOUNDS. 295

XXVIII.-The Effect of Constitution on the Rotatory Power of Optically Active Ammonium Compounds. Part II.

By Humphrey Owen Jones and John Robertshaw Hill.

$\mathrm{I}_{\mathrm{N}}$ a former communication (Trans., 1906, 89, 282) by Miss M. B. Thomas and one of us, the determination of the value of the rotatory powers of the ions of ten substituted ammonium compounds was described. These compounds formed two sets of five, all owing their activity to the presence of an asymmetric nitrogen atom attached to four alkyl groups; in one set, the phenyl, methyl, and benzyl groups were present together with one of the following alkyl groups : ethyl, $n$ - or iso-propyl, isobutyl or isoamyl ; in the other set of five compounds, the benzyl group was replaced by the allyl group.

The results obtained were discussed with reference to Guye's VOL. XCIII. 
hypothesis as applied to the quinquevalent nitrogen atom, and it was decided that further experiments were necessary before deciding how far the hypothesis applied.

The present paper contains an account of the results obtained in the examination of a set of five substituted ammonium compounds containing the groups: $p$-bromophenyl, methyl, and allyl, together with one of the homologous groups, ethyl, $n$ - or iso-propyl, isobutyl or isoamyl. This set therefore differs from the second set mentioned above by the introduction of a bromine atom into the phenyl group.

The substituted bromoanilines used were all new except one; their preparation and properties have already been described elsewhere by one of us (Hill, Proc. Camb. Phil. Soc., 1907, 14, 166), and it has also been shown (Hill, ibid., 351) that the bromine atom had entered the benzene ring in the para-position with respect to the nitrogen atom.

The methods adopted for the resolution of the compounds and the mode of determining the rotatory power of the ion of the substituted ammonium salt has already been fully described in the former paper on this subject (loc. cit.).

p-Bromophenylmethylethylallylammonium iodide was deposited rapidly from a mixture of $p$-bromomethylethylaniline and allyl iodide in equimolecular proportions. After recrystallising repeatedly from alcohol, it formed colourless, stout prisms melting at $151^{\circ}$ :

$$
\begin{gathered}
0.2248 \text { gave } 0.3100 \mathrm{CO}_{2} \text { and } 0.0900 \mathrm{H}_{2} \mathrm{O} . \quad \mathrm{C}=37.6 ; \mathrm{H}=4.4 . \\
\mathrm{C}_{12} \mathrm{H}_{17} \mathrm{NBrI} \text { requires } \mathrm{C}=37.7 ; \mathrm{H}=4.45 \text { per cent. }
\end{gathered}
$$

p-Bromophenylmethylethylallylammonium d-camphorsulphonate was prepared in the usual way by mixing equivalent quantities of the substituted ammonium iodide and silver $d$-camphorsulphonate and boiling for some time with ethyl acetate and alcohol. After filtering and removing the solvent by evaporating on a water-bath, the residue was allowed to stand in a desiccator, when the $d$-camphorsulphonate readily crystallised. It was recrystallised repeatedly from acetone, and then melted at $153^{\circ}$.

After three recrystallisations, 0.2226 gram dissolved in 15.298 grams of water gave a rotation of $0.32^{\circ}$; hence $[\mathrm{M}]_{\mathrm{D}}+53.4^{\circ}$.*

After six recrystallisations, 0.2175 gram in 15.30 grams of water gave a rotation of $0 \cdot 25^{\circ}$; hence $[\mathrm{M}]_{\mathrm{D}}+42 \cdot 7^{\circ}$.

After nine recrystallisations, 0.2920 gram in 14.99 grams of water gave a rotation of $0.362^{\circ}$; hence $[M]_{D}+45 \cdot 2^{\circ}$.

* All the determinations of rotatory power included in this paper were made in 2-dcm. tubes with a Landolt-Lippich triple field polarimeter, and, unless stated otherwise, the temperature was approximately $15^{\circ}$. 
The iodide precipitated from this solution by the addition of potassium iodide gave a solution in alcohol which was inactive.

Thus the camphorsulphonate remains unresolved on recrystallisation from acetone.

It was afterwards recrystallised from amyl acetate at $100^{\circ}$. After three or four recrystallisations, 0.2154 gram dissolved in 15.54 grams of water gave a rotation of $0.28^{\circ}$; hence $[\mathrm{M}]_{\mathrm{D}}+49^{\circ}$.

Thus the rotatory power is not changed by recrystallising from amyl acetate at $100^{\circ}$.

p-Bromophenylmethylethylallylammonium d-bromocamphorsulphonate was prepared by the interaction of equimolecular proportions of silver $d$-bromocamphorsulphonate and the iodide in boiling acetone. The solution was filtered, evaporated on a water-bath, and allowed to stand in a vacuum desiccator, when it crystallised after some time. Attempts were made to recrystallise it from a large number of solvents and mixtures of solvents, but it invariably separated as an oil. It was next fractionally precipitated from acetone solution by the addition of light petroleum. This was done six times, but it still did not crystal. lise, and the iodide precipitated from a portion was found to be inactive.

The salt of Armstrong and Lowry's bromocamphorsulphonic acid was also prepared, but was not obtained crystalline.

Since it had been shown by Miss Homer (Proc. Camb. Phil. Soc., 1907, $14,196)$ that asymmetric nitrogen compounds can be resolved by means of tartaric acid, it was decided to try this acid in this case.

p-Bromophenylmethylethylallylammonium hydrogen d-tartrate was therefore prepared in the following way. The iodide was dissolved in a mixture of alcohol and water, and slight excess of silver oxide added. After warming and allowing to stand for a short time, the solution was filtered from silver iodide, and an aqueous solution of the calculated quantity of $d$-tartaric acid was added. After evaporating the solution on a water-bath and allowing to stand in a desiccator, the tartrate crystallised. Some difficulty was experienced in finding a solvent from which the tartrate could be recrystallised, but eventually a mixture of alcohol and amyl acetate was found to answer the purpose. Afterwards, as purification of the tartrate proceeded, alcohol alone or a mixture of alcohol and etbyl acetate was used.

Analyses of the tartrate, dried over sulphuric acid in a desiccator, gave the following results :

$0 \cdot 2595$ gave $0.4200 \mathrm{CO}_{2}$ and $0.1298 \mathrm{H}_{2} \mathrm{O} . \mathrm{C}=44 \cdot 10 ; \mathrm{H}=5 \cdot 5$.

$0.1968,0.3190 \mathrm{CO}_{2}, 0 \cdot 1031 \mathrm{H}_{2} \mathrm{O} . \mathrm{C}=44 \cdot 20 ; \mathrm{H}=5.82$.

$\mathrm{C}_{16} \mathrm{H}_{22} \mathrm{O}_{6} \mathrm{NBr}$ requires $\mathrm{C}=47.52 ; \mathrm{H}=5.45$ per cent.

$\mathrm{C}_{16} \mathrm{H}_{22} \mathrm{O}_{6} \mathrm{NBr}, 2 \mathrm{H}_{2} \mathrm{O}$ requires $\mathrm{C}=43.64 ; \mathrm{H}=5.91$ per cent. 
The tartrate melts at about $75^{\circ}$ to a cloudy liquid, which effervesces at about $110^{\circ}$ and becomes clear.

Thus it appears that the salt contains two molecules of water of crystallisation, the high results obtained for carbon probably being due to drying over sulphuric acid. It is remarkable that a salt should retain water of crystallisation in alcoholic solution, but other cases of the same kind have been observed by us and by others.

An attempt was made to estimate the percentage of water by heating the tartrate to $105^{\circ}$, but the weight decreased very slowly and continued to do so indefinitely, showing that decomposition takes place at this temperature.

After five recrystallisations, 0.2435 gram of tartrate, dissolved in 15.52 grams of water, gave $a_{D}+0.21^{\circ}$; hence $[a]_{D}+6.4^{\circ}$ and $[\mathrm{M}]_{\mathrm{D}}+27^{\circ}$.

After seven recrystallisations, $0.2024 \mathrm{gram}$ in 15.30 grams of water gave $a_{D}+0 \cdot 13^{\circ}$; hence $[\alpha]_{D}+4 \cdot 9^{\circ}$ and $[M]_{D}+19 \cdot 8^{\circ}$.

After ten recrystallisations, $0 \cdot 2472$ gram in 15.70 grams of water gave $a_{D}+0.09^{\circ}$; hence $[a]_{D}+2.86^{\circ}$ and $[M]_{D}+11.5^{\circ}$.

After fourteen recrystallisations, $0.2467 \mathrm{gram}$ in 15.31 grams of water gave $\alpha_{D}+0.09^{\circ}$; hence $[a]_{D}+2.8^{\circ}$ and $[M]_{D}+11 \cdot 3^{\circ}$.

After seventeen recrystallisations, $0.2218 \mathrm{gram}$ in $15.21 \mathrm{grams}$ of water gave $a_{D}+0.07^{\circ}$ and $[M]_{D}+9 \cdot 7^{\circ}$.

Further recrystallisation did not seem to effect any measurable change.

The $[\mathrm{M}]_{\mathrm{D}}$ for $\mathrm{C}_{16} \mathrm{H}_{22} \mathrm{O}_{6} \mathrm{NBr}, 2 \mathrm{H}_{2} \mathrm{O}$, which corresponds with [M] $10^{\circ}$ for $\mathrm{C}_{16} \mathrm{H}_{22} \mathrm{O}_{6} \mathrm{NBr}$, is $10^{\circ}$.

Taking $[\mathrm{M}]_{\mathrm{D}}$ for the ion $\mathrm{C}_{4} \mathrm{H}_{4} \mathrm{O}_{6} \mathrm{H}$ as $42^{\circ}$, from the results of Landolt on ammonium hydrogen tartrate, we get $[M]_{\mathrm{D}}$ for the ion $\mathrm{C}_{6} \mathrm{H}_{4} \mathrm{Br} \cdot \mathrm{CH}_{3} \cdot \mathrm{C}_{2} \mathrm{H}_{5} \cdot \mathrm{C}_{3} \mathrm{H}_{5} \cdot \mathrm{N}$ - as about $-31^{\circ}$.

The results on the whole are not very satisfactory, since the observed rotatory power is too small to enable us to determine whether the rotatory power is really constant, and a determination of the influence of temperature on the rotatory power is a hopeless task with such small readings. Attempts are being made to resolve this compound by means of other acids, in the hope of obtaining more satisfactory results.

The active iodide recovered from the tartrate melted at $142-143^{\circ}$, and was lævorotatory. So little of the iodide was obtained that trustworthy determinations of the rotatory power could not be made, but $[\mathrm{M}]_{\mathrm{D}}$ appears to be about $-20^{\circ} ;[\mathrm{M}]_{\mathrm{D}}$ for the same specimen in chloroform was $-26 \cdot 6^{\circ}$, and autoracemisation occurred.

p-Bromoplenylmethyl-n-propylallylammonium iodide was readily deposited in a crystalline state from a mixture of $p$-bromomethylethylaniline and allyl iodide in equimolecular proportions. The salt was 
readily recrystallised from alcohol, and separated in thin, colourless plates, usually hexagonal in shape, which melted at $140^{\circ}$ :

0.2002 gave $0.2905 \mathrm{CO}_{2}$ and $0.0874 \mathrm{H}_{2} \mathrm{O}$. $\mathrm{C}=39 \cdot 5 ; \mathrm{H}=4 \cdot 85$.

$\mathrm{C}_{13} \mathrm{H}_{19} \mathrm{NBrI}$ requires $\mathrm{C}=39 \cdot 4 ; \mathrm{H}=4.80$ per cent.

p-Bromophenylmethyl-n-propylallylammonium d-camphorsulphonate was prepared in the usual way, and was found to crystallise readily. When recrystallised repeatedly from either hot or cold ethyl acetate, it was found that the rotatory power of the salt in aqueous solution did not change appreciably, and did not differ much from that of the acid ion, as may be seen from the following determination :

0.3061 gram in 12.736 grams of solution gave $\alpha_{\mathfrak{D}}+0.51^{\circ}$; hence $[a]_{\mathrm{D}}+10^{\circ} 6^{\circ}$ and $[\mathrm{M}]_{\mathrm{D}}+53 \cdot 0^{\circ}$.

The camphorsulphonate melts at $161-162^{\circ}$, but was not further examined, as the desired resolution was effected readily by means of the bromocamphorsulphonate.

p-Bromophenylmethyl-n-propylallylammonium d-bromocamphorsulphonate was prepared in the usual way, and was found to crystallise after standing for some time in a vacuum desiccator. The salt was crystallised at first from acetone and a little toluene, then, as its solubility in acetone diminished, acetone alone was used, and finally, in some cases only, acetone containing a trace of alcohol was used as solvent.

The melting point of the salt rose gradually, until it became constant at $159-160^{\circ}$, and the molecular rotatory power of the salt also increased and became constant at $416^{\circ}$ after about three or four crystallisations. Analysis of the salt gave the following result :

0.2173 gave $0.3825 \mathrm{CO}_{2}$ and $0.1145 \mathrm{H}_{2} \mathrm{O} . \quad \mathrm{C}=48 \cdot 0 ; \mathrm{H}=5.85$. $\mathrm{C}_{23} \mathrm{H}_{33} \mathrm{O}_{4} \mathrm{NBr}_{2} \mathrm{~S}$ requires $\mathrm{C}=47 \cdot 8 ; \mathrm{H}=5 \cdot 70$ per cent.

Since the rotatory power of the basic ion in this salt proves to be less than that of the corresponding isopropyl ion, and in the corresponding phenyl series previously described (loc. cit., p. 297) the rotatory powers of the $n$ - and iso-propyl compounds were almost identical, special precautions were taken to see that the resolution was complete. The salt was resolved on three separate occasions, and cold and hot acetone with and without alcohol used as solvent, but in all cases the same result was obtained.

The following experiments suffice to prove that the separation is as complete as possible :

After three crystallisations, $0 \cdot 1180$ gram in $11 \cdot 269$ grams of solution gave $\alpha_{D}+1 \cdot 51^{\circ}$; hence $[a]_{D}+72 \cdot 1^{\circ}$ and $[M]_{D}+417^{\circ}$.

After two further crystallisations from cold acetone, $0.1180 \mathrm{gram}$ in 11.621 grams of solution gave $\alpha_{D}+1.46^{\circ}$; hence $[a]_{D}+71.9^{\circ}$ and $[\mathrm{M}]_{\mathrm{D}}+416^{\circ}$. 
After two further crystallisations from warm acetone, containing a trace of alcohol, 0.1581 gram in 11.235 grams of solution gave $\alpha_{D}+2 \cdot 00^{\circ}$; hence $[a]_{D}+71 \cdot 0^{\circ}$ and $[M]_{D}+412^{\circ}$.

These determinations and several others were carried out at the ordinary temperature of about $15^{\circ}$, and show that the molecular rotatory power of the salt may be taken as $416^{\circ}$ at this temperature; taking that of the acid ion as $275^{\circ}$, the molecular rotatory power of the basic ion is obtained as $141^{\circ}$.

The influence of temperature on the rotatory power was then determined on a specimen of salt which gave a value of $[M]_{\mathrm{D}}+417^{\circ}$ at $15^{\circ}$.

0.1790 Gram in 16.022 grams of solution gave the following results (the salt is rather sparingly soluble in water, and this solution was practically saturated) :

$\begin{array}{rrrrc}t . & \boldsymbol{a}_{\mathrm{D} \cdot} & {[\alpha]_{\mathrm{D}}} & {[\mathrm{M}]_{\mathrm{D}}} & {[\mathrm{M}]_{\mathrm{D}} \text { for basic ion. }} \\ 6^{\circ} & 1.62^{\circ} & 72 \cdot 5^{\circ} & 420^{\circ} & 148^{\circ} \\ 12 & 1.61 & 72 \cdot 0 & 417 & 143 \\ 25 & 1.60 & 71.6 & 414 & 134 \\ 45 & 1.56 & 70.6 & 409 & 120\end{array}$

The densities in all these dilute solutions are practically identical with those of water at the same temperature.

d-p-Bromophenylmethyl-n-propylallylammonium iodide was precipitated as colourless plates on the addition of a very concentrated potassium iodide solution to the saturated solution of the bromocamphorsulphonate. On account of the sparing solubility of the latter salt, only a small proportion of the iodide could be obtained.

The active iodide melts at $142-143^{\circ}$, whether taken as precipitated or after crystallising from cold alcohol.

Determinations of its rotatory power were made in solution in alcohol and in chloroform; the iodide is very sparingly soluble in the latter solvent, so that good values could not be obtained. The active iodide, like all those hitherto examined, undergoes autoracemisation in chloroform.

In ethyl alcohol at $15^{\circ}$ :

$0.118 \mathrm{gram}$ in 9.377 grams of solution gave $a_{\mathrm{D}}+0.73^{\circ}$ (density $=$ $0.810)$; hence $[a]_{\mathrm{D}}+35 \cdot 8^{\circ}$ and $[\mathrm{M}]_{\mathrm{D}}+142^{\circ}$.

0.122 gram in. 9.661 grams of solution gave $a_{D}+0.76^{\circ}$ (density $\Rightarrow$ $0.811)$; hence $[a]_{\mathrm{D}}+37 \cdot 1^{\circ}$ and $[\mathrm{M}]_{\mathrm{D}}+147^{\circ}$.

0.118 gram in 9.270 grams of solution gave $a_{D}+0.75^{\circ}$ (density $=$ $0 \cdot 810)$; hence $[a]_{\mathrm{D}}+36 \cdot 4^{\circ}$ and $[\mathrm{M}]_{\mathrm{D}}+144^{\circ}$.

The value of the molecular rotatory power in ethyl alcohol may therefore be taken as $144^{\circ}$. 
In chloroform :

0.0781 gram in 16.85 grams of solution gave $\alpha_{\mathrm{D}}+0.80^{\circ}$ (density $=$ $1 \cdot 494)$; hence $[a]_{\mathrm{D}}+57 \cdot 9^{\circ}$ and $[\mathrm{M}]_{\mathrm{D}}+229^{\circ}$.

$0 \cdot 1080$ gram in 16.532 grams of solution gave $a_{\mathrm{D}}+1 \cdot 10^{\circ}$ (density $=$ $1.500)$; hence $[a]_{\mathrm{D}}+56.2^{\circ}$ and $[\mathrm{M}]_{\mathrm{D}}+222^{\circ}$.

Hence we may take the value of $[\mathrm{M}]_{\mathrm{D}}$ to be about $226^{\circ}$ in chloroform, a value rather unusually large compared with that obtained in alcohol.

The rotatory power of these chloroform solutions fell to about threefourths value in four hours, nine-sixteenths in nine hours, and became almost inactive in about forty-eight hours and quite inactive between forty-eight and seventy-two hours.

p-Bromophenylmethylisopropylallylammonium iodide.-A mixture of the calculated quantities of $p$-bromomethylisopropylaniline and allyl iodide gradually deposited crystals of the quaternary iodide on standing. After recrystallising several times from alcohol, the salt formed colourless, rectangular prisms or rhombs, melting at $153^{\circ}$ :

0.2142 gave $0.3075 \mathrm{CO}_{2}$ and $0.0978 \mathrm{H}_{2} \mathrm{O} . \mathrm{C}=39 \cdot 15 ; \mathrm{H}=5.07$. $\mathrm{C}_{13} \mathrm{H}_{19} \mathrm{NBrI}$ requires $\mathrm{C}=39 \cdot 4 ; \mathrm{H}=4.80$ per cent.

p-Bromophenylmethylisopropylallylammonium d-camphorsulphonate was prepared by heating together calculated quantities of the iodide and silver $d$-camphorsulphonate with moist acetone. After filtering off the silver iodide, the acetone was evaporated, and the salt crystallised readily on standing a very short time. The camphorsulphonate was first recrystallised a few times from a mixture of acetone and toluene, then from acetone alone, and finally, as it became less soluble, from acetone and water.

After nine recrystallisations, 0.2248 gram of the salt in 15.4 grams solution gave $a_{\mathrm{D}}-0.01^{\circ}$; hence $[\mathbf{M}]_{\mathrm{D}}-1.7^{\circ}$

After twelve recrystallisations, $0 \cdot 2560$ gram in $16 \cdot 46$ grams of solution gave $a_{\mathrm{D}}-0.02^{\circ}$; hence $[\mathrm{M}]_{\mathrm{D}}-3 \cdot 2^{\circ}$.

After four more recrystallisations, $0.2272 \mathrm{gram}$ in $15.28 \mathrm{grams}$ of solution gave $\alpha_{\mathrm{D}}-0.11^{\circ}$; hence $[\mathrm{M}]_{\mathrm{D}}-18.5^{\circ}$.

Thus it appeared that the $l B d A$ salt was being isolated, but the rotatory power was not yet constant, and it was clear that large quantities of the salt would have to be worked up. The salt melted at $163^{\circ}$ :

$$
\begin{gathered}
0.1760 \text { gave } 0.3572 \mathrm{CO}_{2} \text { and } 0.1087 \mathrm{H}_{2} \mathrm{O} . \mathrm{C}=55.35 ; \mathrm{H}=6.86 . \\
\mathrm{C}_{23} \mathrm{H}_{34} \mathrm{O}_{4} \mathrm{NBrS} \text { requires } \mathrm{C}=55.20 ; \mathrm{H}=6.8 \text { per cent. }
\end{gathered}
$$

Some time later, another attempt was made to resolve this salt. The salt from the mother liquors together with same freshly-prepared salt was recrystallised from acetone and a few drops of alcohol, as it was so sparingly soluble in acetone alone. The salt was now found to be 
strongly dextrorotatory, and it therefore appeared that the $d B d A$ salt was being obtained.

After six recrystallisations, 0.2206 gram in 14.83 grams of water gave $\alpha_{\mathrm{D}}+1 \cdot 28^{\circ}$; hence $[\mathrm{M}]_{\mathrm{D}}+215 \cdot 2^{\circ}$.

After eight recrystallisations, 0.2472 gram in 14.85 grams of water gave $\alpha_{\mathrm{D}}+1 \cdot 41^{\circ}$; hence $[\mathrm{M}]_{\mathrm{D}}+212^{\circ}$.

After ten recrystallisations, 0.1977 gram in 14.88 grams of water gave $a_{D}+1 \cdot 13^{\circ}$; hence $[\mathrm{M}]_{\mathrm{D}}+212 \cdot 7^{\circ}$.

Thus it appears that the molecular rotatory power becomes constant at about $213^{\circ}$. This gives the value of $[\mathrm{M}]_{D}$ for the basic ion as $161^{\circ}$.

We have not yet been able to find the explanation of these curious observations, and have not been able on subsequent occasions to isolate the $l B d A$ salt ; the $d B d A$ salt when recrystallised from acetone and water did not become lævorotatory. The rotatory power of the $d B d A$ salt was observed at different temperatures.

0.2395 Gram dissolved in 16.085 grams of water gave the following rotations (density $=1.002$ at $\left.15^{\circ}\right)$ :

$\begin{array}{rcccc}t . & \boldsymbol{\alpha}_{\mathrm{D} \cdot} & {[\alpha]_{\mathrm{D} \cdot}} & {[\mathrm{M}]_{\mathrm{D} \cdot}} & {[\mathrm{M}]_{\mathrm{D}} \text { for basic ion. }} \\ 3^{\circ} & 1 \cdot 30^{\circ} & 43 \cdot 5^{\circ} & 217 \cdot 5^{\circ} & 169 \cdot 5^{\circ} \\ 10 & 1 \cdot 28 & 42 \cdot 9 & 215 \cdot 0 & 165 \cdot 5 \\ 20 & 1 \cdot 25 & 41 \cdot 9 & 210 \cdot 0 & 158 \cdot 5 \\ 30 & 1 \cdot 22 & 40 \cdot 9 & 205 \cdot 0 & 151 \cdot 4 \\ 40 & 1 \cdot 20 & 40 \cdot 2 & 203 \cdot 0 & 147 \cdot 4 \\ 50 & 1 \cdot 18 & 39 \cdot 5 & 200 \cdot 0 & 142 \cdot 4\end{array}$

The corresponding $d$-bromocamphorsulphonate was prepared, but did not crystallise.

d-Bromophenylmethylisopropylallylammonium iodide was readily precipitated from an aqueous solution of the resolved camphorsulphonate by addition of concentrated potassium iodide solution. It melts at $153^{\circ}$, the same temperature as the inactive iodide.

The following determinations of its rotatory power in ethyl-alcoholic solution were made at $15^{\circ}$ :

0.1154 gram in 12.69 grams of alcohol gave $a_{D}+0.60^{\circ}$ (density $=$ $0.810)$; hence $[a]_{D}+40.7^{\circ}$ and $[M]_{D}+165^{\circ}$.

0.2073 gram in 22.72 grams of alcohol gave $a_{\mathrm{D}}+0.59^{\circ}$ (density $=$ $0.81)$; hence $[a]_{D}+39.9^{\circ}$ and $[M]_{D}+162^{\circ}$.

This iodide was very sparingly soluble in chloroform, and it was therefore not found possible to determine the rotatory power in this solvent.

p-Bromophenylmethylisobutylallylammonium iodide was deposited very slowly on mixing $p$-bromomethylisobutylaniline with allyl iodide in equimolecular proportions. This salt was very soluble in alcohol, and crystallised with difficulty. It was recrystallised from acetone or 
from alcohol and ether, when it separated as microscopic prisms, melting at $135-136^{\circ}$ :

$$
\begin{gathered}
0.2485 \text { gave } 0.3745 \mathrm{CO}_{2} \text { and } 0 \cdot 1207 \mathrm{H}_{2} \mathrm{O} . \quad \mathrm{C}=41 \cdot 10 ; \mathrm{H}=5 \cdot 39 \text {. } \\
\mathrm{C}_{14} \mathrm{H}_{21} \mathrm{NBrI} \text { requires } \mathrm{C}=40 \cdot 97 ; \mathrm{H}=5 \cdot 12 \text { per cent. }
\end{gathered}
$$

The d-camphorsulphonate was prepared and recrystallised repeatedly from acetone and light petroleum, but its molecular rotatory power was then found to be only just above $60^{\circ}$; further examination of this salt was abandoned, as the desired result was obtained by means of the bromocamphorsulphonate.

p-Bromophenylmethylisobutylallylammonium d-bromocamphorsulphonate was prepared by heating together the calculated quantities of silver $d$-bromocamphorsulphonate and the iodide in moist acetone. It crystallised readily from the filtrate after evaporating on a waterbath. It was recrystallised from acetone, in which it is readily soluble, or from acetone and light petroleum; the bromocamphorsulphonate melts at $138^{\circ}$ :

$0 \cdot 2110$ gave $0.3750 \mathrm{CO}_{2}$ and $0.1145 \mathrm{H}_{2} \mathrm{O}$. $\mathrm{C}=48 \cdot 5 ; \mathrm{H}=6.03$. $\mathrm{C}_{24} \mathrm{H}_{35} \mathrm{O}_{4} \mathrm{NBr}_{2} \mathrm{~S}$ requires $\mathrm{C}=48 \cdot 6 ; \mathrm{H}=5.91$ per cent.

The rotatory power of the salt gradually increased on recrystallisation, showing that the $d B d A$ salt was being obtained. It was found very difficult to obtain a constant rotatory power, and several attempts had to be made, in which large quantities of the salt were used and the salt in the mother liquors was carefully worked up.

After about twenty-five recrystallisations, 0.1044 gram in 11.045 grams of water gave $\alpha_{\mathrm{D}}+1 \cdot 16^{\circ}($ density $=1.001)$; hence $[a]_{\mathrm{D}}+61 \cdot 3^{\circ}$ and $[\mathrm{M}]_{\mathrm{D}}+364^{\circ}$.

After two more recrystallisations from acetone and light petroleum, 0.1027 gram in 11.007 grams of water gave $a_{D}+1.15^{\circ}$; hence $[a]_{\mathrm{D}}+61 \cdot 6^{\circ}$ and $[\mathrm{M}]_{\mathrm{D}}+366^{\circ}$.

After three more recrystallisations :

0.1250 gram in 11.37 grams of water gave $a_{D}+1 \cdot 36^{\circ}$; hence $[a]_{D}+61 \cdot 8^{\circ}$ and $[M]_{D}+366^{\circ}$.

$0 \cdot 1996$ gram in $11 \cdot 145$ grams of water gave $a_{D}+2 \cdot 25^{\circ}$; hence $[a]_{\mathrm{D}}+62 \cdot 8^{\circ}$ and $[\mathrm{M}]_{\mathrm{D}}+372^{\circ}$.

$0 \cdot 1198$ gram in 11.42 grams of water gave $\alpha_{D}+1 \cdot 32^{\circ}$; hence $[\alpha]_{\mathrm{D}}+62 \cdot 9^{\circ}$ and $[\mathrm{M}]_{\mathrm{D}}+373^{\circ}$.

Thus $[M]_{D}$ for the salt is $370^{\circ}$ and for the basic ion is $95^{\circ}$.

The influence of temperature on the rotatory power of the salt was almost negligible, hence the following values may be taken for the molecular rotatory power of the ion: $103^{\circ}$ at $0^{\circ}, 95^{\circ}$ at $15^{\circ}, 86^{\circ}$ at $30^{\circ}$, and $76^{\circ}$ at $50^{\circ}$. These values are almost identical with those obtained for the corresponding isoamyl ion.

d-Bromophenylmethylisobuiylallylammonium iodide was readily pre- 
cipitated from an aqueous solution of the bromocamphorsulphonate of constant rotatory power by the addition of concentrated potassium iodide solution. It melts at $133-134^{\circ}$, and separates from alcohol in small prisms.

The following determinations of the rotatory power in alcohol were made at about $15^{\circ}$ :

0.1515 gram in 12.71 grams of alcohol gave $a_{D}+0.53^{\circ}$ (density $=$ $0.810)$; hence $[a]_{\mathrm{D}}+27 \cdot 4^{\circ}$ and $[\mathrm{M}]_{\mathrm{D}}+112^{\circ}$.

After recrystallising from cold alcohol :

0.160 gram in 9.587 grams of solution gave $a_{D}+0.77^{\circ}$ (density $=$ $0.815)$; hence $[\alpha]_{D}+28.3^{\circ}$ and $[\mathrm{MY}]_{\mathrm{D}}+116^{\circ}$.

$0 \cdot 1501$ gram in 9.687 grams of solution gave $\alpha_{\mathrm{D}}+0.73^{\circ}$ (density $=$ $0.816)$; hence $[a]_{D}+28.9^{\circ}$ and $[M]_{D}+118^{\circ}$.

The value of $[M]_{D}$ for the iodide in ethyl-alcoholic solution may therefore be taken as about $117^{\circ}$.

The active iodide is so sparingly soluble in chloroform that no trustworthy determinations of the rotatory power could be made. The following experiment, however, seems to show that the iodide has a greater rotatory power in chloroform than in alcohol, and that it undergoes autoracemisation :

0.029 gram in 17.916 grams of solution (practically saturated) gave $a_{D}+0.23^{\circ}$ (density $\left.=1 \cdot 490\right)$; hence $[a]_{D}+47 \cdot 7^{\circ}$ and $[M]_{D}+195^{\circ}$.

After four hours, $a_{D}$ was $0 \cdot 16^{\circ}$, and after forty-eight hours the solution was inactive.

p-Bromophenylmethylisoamylallylammonium iodide was prepared from the tertiary amine and allyl iodide. It was somewhat soluble in alcohol, and was therefore recrystallised from a mixture of alcohol and ether, from which it separated in sheaf-like aggregates of long, colourless prisms, melting at $127-128^{\circ}$ :

0.2962 gave $0.4581 \mathrm{CO}_{2}$ and $0.1435 \mathrm{H}_{2} \mathrm{O} . \mathrm{C}=42 \cdot 2 ; \mathrm{H}=5.38$.

$\mathrm{C}_{15} \mathrm{H}_{23} \mathrm{NBrI}$ requires $\mathrm{C}=42.4 ; \mathrm{H}=5.42$ per cent.

The corresponding bromide was also prepared by the union of the amine and allyl bromide and recrystallised from alcohol and ether, when it formed colourless prisms melting at $161-162^{\circ}$ :

0.2891 gave $0.5075 \mathrm{CO}_{2}$ and $0.1615 \mathrm{H}_{2} \mathrm{O}$. $\mathrm{C}=47.9 ; \mathrm{H}=6.21$. $\mathrm{C}_{15} \mathrm{H}_{23} \mathrm{NBr}_{2}$ requires $\mathrm{C}=47.8 ; \mathrm{H}=6.10$ per cent.

p-Bromophenylmethylisoamylallylammonium d-camphorsulphonate was prepared by boiling together equivalent quantities of the bromide or iodide and silver $d$-camphorsulphonate with moist acetone. The salt did not crystallise well, and after recrystallising several times from a mixture of acetone and toluene it was still somewhat viscid and melted at $65^{\circ}$. 
POWER OF OPTICALLY ACTIVE AMMONIUM COMPOUNDS. 305

From the following determination of its rotatory power, it is clear that resolution does not take place rapidly, if at all :

0.2000 gram in 12.83 grams of solution gave $a_{D}+0.26^{\circ}$; hence $[\mathrm{M}]_{\mathrm{D}}+44^{\circ}$.

The bromocamphorsulphonate was therefore made, and it was found that this could be resolved more easily.

p-Bromophenylmethylisoamylallylammonium d-bromocamphorsulphonaie was prepared in the usual way, using moist acetone as solvent ; it crystallised readily, and could be recrystallised from acetone. After repeated recrystallisation from acetone, the salt formed stellate aggregates of needles and melted sharply at $170^{\circ}$ :

0.2550 gave $0.4641 \mathrm{CO}_{2}$ and $0.1378 \mathrm{H}_{2} \mathrm{O} . \mathrm{C}=49 \cdot 6 ; \mathrm{H}=6.00$. $\mathrm{C}_{25} \mathrm{H}_{37} \mathrm{O}_{4} \mathrm{NBr}_{2} \mathrm{~S}$ requires $\mathrm{C}=49 \cdot 4 ; \mathrm{H}=6.10$ per cent.

It was found that the molecular rotatory power of the salt increased to about $360^{\circ}$ after three or four recrystallisations from ethyl acetate or acetone, and further recrystallisation only served to raise the rotatory power to $370^{\circ}$. As this value is very close to that found for the isobutyl compound, the salt was repeatedly recrystallised both from hot and cold acetone and from cold ethyl acetate, and examined in order to make certain that resolution was complete and the rotatory power constant.

After six recrystallisations from warm acetone:

$0.1330 \mathrm{gram}$ in 11.600 grams of solution gave $a_{\mathrm{D}}+1.39^{\circ}$ (density $=$ $1.001\rangle$; hence $[a]_{\mathrm{D}}+60 \cdot 6^{\circ}$ and $[\mathrm{M}]_{\mathrm{D}}+368^{\circ}$.

After two further recrystallisations from cold acetone :

0.121 gram in 11.934 grams of solution gave $\alpha_{\mathrm{p}}+1.32^{\circ}$ (density $=$ $1 \cdot 001)$; hence $[a]_{\mathrm{D}}+60 \cdot 1^{\circ}$ and $[\mathrm{M}]_{\mathrm{D}}+365^{\circ}$.

After two further recrystallisations from warm acetone:

$0 \cdot 1611$ gram in 11.332 grams of solution gave $a_{\mathfrak{D}}+1 \cdot 74^{\circ}($ density $=$ $1 \cdot 002)$; hence $[a]_{\mathrm{D}}+61 \cdot 1^{\circ}$ and $[\mathrm{M}]_{\mathrm{D}}+371^{\circ}$.

The salt was now recrystallised from ethyl acetate, and successive fractions examined :

0.104 gram in 11.807 grams of solution gave $\alpha_{\mathcal{D}}+1.08^{\circ}$ (density $=$ $1 \cdot 000)$; hence $[\alpha]_{\mathrm{D}}+61 \cdot 1^{\circ}$ and $[\mathrm{M}]_{\mathrm{D}}+371^{\circ}$.

0.1019 gram in 11.604 grams of solution gave $\alpha_{\mathfrak{D}}+1.07^{\circ}$ (density $=$ $1 \cdot 000)$; hence $[\alpha]_{\mathrm{D}}+60.8^{\circ}$ and $[\mathrm{M}]_{\mathrm{D}}+369^{\circ}$.

It is clear that the salt was as pure as recrystallisation could make it; hence the molecular rotatory power may be taken as $369^{\circ}$ at $16^{\circ}$, and $[\mathrm{M}]_{\mathrm{D}}$ for the basic ion is therefore $94^{\circ}$.

The following results were obtained in determining the influence of temperature on the rotatory power of the salt. 
0.1829 gram in 15.845 grams of solution (density at $15^{\circ}=1.002$ ) :

$\begin{array}{ccccc}t . & a_{D^{*}} & {[\alpha]_{D^{*}}} & {[M]_{D^{*}}} & {[M]_{\mathrm{D}} \text { for basic ion. }} \\ 10^{\circ} & 1 \cdot 42^{\circ} & 61.4^{\circ} & 372^{\circ} & 99^{\circ} \\ 22 & 1 \cdot 41 & 61.0 & 370 & 92 \\ 35 & 1 \cdot 40 & 60.6 & 368 & 84 \\ 50 & 1.38 & 60.3 & 366 & 75\end{array}$

d-Bromophenylmethylisoamylallylammonium iodide.-When a concentrated solution of potassium iodide was added to a solution of the bromocamphorsulphonate, the solution became turbid and oily drops separated; on standing these became crystalline. The colourless crystals of the iodide when dried melted at $130-131^{\circ}$, and after crystallising from cold alcohol formed colourless prisms melting at $131-131 \cdot 5^{\circ}$.

The rotatory power was determined in alcohol and in chloroform at about $15^{\circ}$. In alcohol :

0.124 gram in 8.702 grams of solution gave $a_{D}+0.60^{\circ}$ (density $=$ $0 \cdot 810)$; hence $[a]_{D}+26 \cdot 3^{\circ}$ and $[M]_{D}+111^{\circ}$.

0.112 gram in 9.220 grams of solution gave $a_{D}+0.49^{\circ}$ (density $=$ $0.809)$; hence $[a]_{\mathrm{D}}+25 \cdot 2^{\circ}$ and $[\mathrm{M}]_{\mathrm{D}}+107^{\circ}$.

0.1221 gram in 9.468 grams of solution gave $a_{D}=0.55^{\circ}$ (density $=$ $0.814)$; hence $[\alpha]_{\mathrm{D}}+26 \cdot 2^{\circ}$ and $[\mathrm{M}]_{\mathrm{D}}+111^{\circ}$.

0.1409 gram in 9.347 grams of solution gave $[a]_{D}+0.64^{\circ}$ (density $=$ $0 \cdot 81)$; hence $[\alpha]_{D}+26 \cdot 2^{\circ}$ and $[M]_{D}+111^{\circ}$.

Therefore the molecular rotatory power of the iodide may be taken as $111^{\circ}$.

In chloroform :

0.121 gram in 16.610 grams of solution gave $[\alpha]_{\mathrm{D}}+0.87^{\circ}$ (density $=$ $1 \cdot 495)$; hence $[a]_{D}+39.9^{\circ}$ and $[M]_{D}+169^{\circ}$.

After two and a-half hours, $a_{D}+0.78^{\circ}$; after twenty-two hours, $a_{\mathrm{D}}+0 \cdot 15^{\circ}$, and after forty-eight hours the solution was inactive.

The following table, containing the melting points and rotatory powers of the compounds described in this paper, is given for convenience of reference :

\section{p-Bromophenyl-methyl-allyl Series.}

\begin{tabular}{|c|c|c|c|c|c|c|}
\hline & $\begin{array}{l}\text { M. p. of } \\
\text { active } \\
\text { iodide. }\end{array}$ & $\begin{array}{l}\text { M. p. of } \\
d \text {-camphor- } \\
\text { sulphonate. }\end{array}$ & $\begin{array}{l}\text { M. p. of } \\
d \text {-bromo- } \\
\text { camphor- } \\
\text { sulphonate. }\end{array}$ & $\begin{array}{c}{[M]_{D} \text { of }} \\
\text { ion } \\
\text { at } 15^{\circ} .\end{array}$ & $\begin{array}{l}{[\mathrm{M}]_{\mathrm{D}} \text { of }} \\
\text { iodide in } \\
\text { alcohol. }\end{array}$ & $\begin{array}{c}{[\mathrm{M}]_{\mathrm{D}} \text { of }} \\
\text { iodide in } \\
\text { chloroform. }\end{array}$ \\
\hline 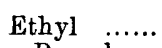 & $161^{\circ}$ & $153^{\circ}$ & - & $-31^{\circ}(?)$ & $-20^{\circ}(?)$ & $-26^{\circ}(?)$ \\
\hline Propyl ... & $142-143$ & $161-162$ & $159-160^{\circ}$ & 141 & 144 & 222 \\
\hline & $133-13$ & 100 & $\overline{138}$ & $\begin{array}{r}101 \\
96\end{array}$ & 117 & 195 \\
\hline oAmyl & $135-136$ & $65(?)$ & 170 & 94 & 111 & 169 \\
\hline
\end{tabular}

The great similarity in the melting points of several of the 
POWER OF OPTICALLY ACTIVE AMMONIUM COMPOUNDS, 307

compounds is as marked as in the corresponding set of phenyl compounds.

It will be seen from the table that the value of $[M]_{D}$ for the iodide in alcohol is in each case greater than that of the basic ion in water, and that the value of $[\mathbf{M}]_{D}$ of the iodide is greater in chloroform solution than in alcohol. The latter statement is also true for all the active iodides examined in the former communication on this subject (loc. cit., p. 304), and the first-mentioned relation is also true with one exception for the compounds then examined.

The following diagram shows that the influence of temperature on

FIG. 1.

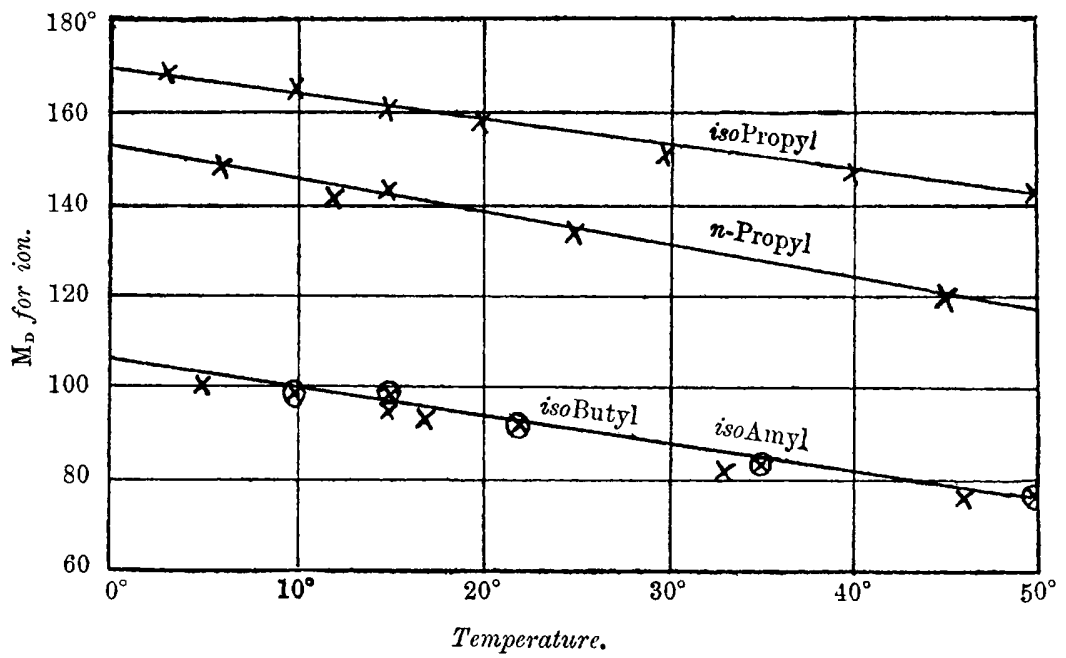

In the case of the isobutyl and isoamyl compounds, the points marked $\oplus$ refer to the isobutyl compound.

the rotatory powers of the ions is uniform throughout the range examined and of the same kind in all five cases.

The relation between the values of the molecular rotatory powers of the ions and the values of the product of asymmetry for the asymmetric nitrogen atom or ion may now be discussed.

The formula for the product of asymmetry, $p^{\prime \prime}$, in terms of the masses of the four allyl groups developed in the former communication (loc. cit., p. 308) :

$$
p^{\prime \prime}=\frac{\{(a+d)-(b+c)\}\{(a+b)-(c+d)\}(a-c)(b-d)}{(a+b+c+d)^{4}}
$$


applied to the three possible configurations for this series of compounds :
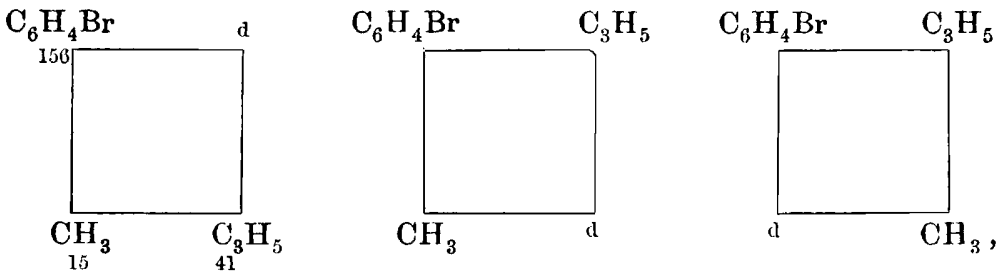

where $d$ represents the group which is varied, gives the values for $p^{\prime \prime}$ given in the following table, which also contains the values of $[M]_{D}$ for the basic ions at $15^{\circ}$.

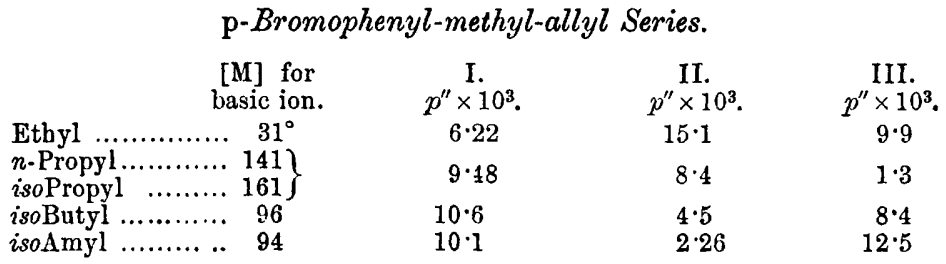

It is clear that there is no simple relation between the values of $p^{\prime \prime}$ and $[M]_{D}$ even if, for the present, the somewhat doubtful values for the ethyl compound were neglected, and in this case no connexion can be seen even if the different compounds be assumed to possess different configurations.

The data given for the isobutyl and isoamyl compounds leave some slight doubt as to which ion has the greater rotatory power. Taking into consideration the fact that the iodide of the isobutyl compound has the greater rotatory power, it seems very probable that the basic ion also has a greater rotatory power than the corresponding ion containing the isoamyl group, especially as the evidence of complete resolution is more conclusive in the latter case.

The similarity of the rotatory powers of the isobutyl and isoamyl compounds is remarkable, and would seem to suggest that they have configuration I, but then the value of $p^{\prime \prime}$ is greater than that for the propyl compounds. It is interesting to note also that, although in the phenyl-methyl-allyl series the rotatory powers of the $n$-propyl and isopropyl compounds were found to be almost identical, in this series the $n$ - and iso propyl compounds differ in the same way as they do in the phenyl-methyl-benzyl series, where the values of $[M]_{\mathfrak{D}}$ for the ions were found to be $299^{\circ}$ and $398^{\circ}$ respectively.

A similar case in which the isopropyl compound has a greater rotatory power than the n-propyl compound has recently been found 
MCKENZIE AND WREN : THE PREPARATION OF L-BENZOIN. 309

by Piutti and Magli in the alkyl hydrogen aspartates (Gazzetta, 1906, 36, ii, 738).

The series of compounds derived from the same substituted $p$-bromoanilines, but containing the benzyl instead of the allyl group, is also under examination, and the results of the examination of these and other active nitrogen compounds will be communicated to the Society later.

The expenses of this investigation have been defrayed by grants placed at our disposal by the Government Grant Committee of the Royal Society, for which we are glad to make this grateful acknowledgment.

\author{
University Chemical Laboratory, \\ CAMBRIDGE.
}

